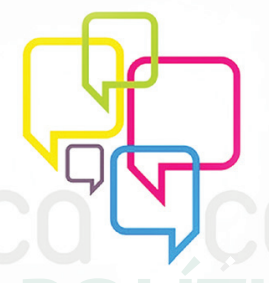

\title{
Monitoramento nas Mídias Sociais: Um estudo sobre Comunicação Política e Eleições Presidenciais Brasileiras em 2014 ${ }^{1}$
}

Monitoreo de los Medios de Comunicación Social: Un estudio sobre

Comunicación Política y Elecciones Presidenciales en Brasil en 2014

Monitoring the Social Media: A study on

Political Communication and Brazilian Presidential Elections in 2014

\author{
Victor Kraide Corte REAL ${ }^{2}$
}

\begin{abstract}
RESUMO
Diante do grande volume de informação propagado atualmente via internet, as pesquisas sobre comunicação política e eleições não podem se restringir aos métodos convencionais de coleta e análise de dados. É necessário que os pesquisadores invistam e tomem contato com novas abordagens a respeito das manifestações postadas a cada segundo nas Redes Sociais Online. Para tanto, devemos recorrer aos modernos e eficazes sistemas de Monitoramento disponíveis no mercado. O presente estudo exemplifica o uso de um desses sistemas.
\end{abstract}

Palavras-chave: Esfera Pública; Capital Social; Conversação; Internet; Big Data.

\section{RESUMEN}

Con el gran volumen de información que se propaga a través de Internet en la actualidad, la investigación sobre la comunicación y las elecciones político no puede limitarse a los métodos convencionales de recolección y análisis de datos. Es necesario que los investigadores invierten y toman contacto con nuevos enfoques en relación con los sucesos publicado cada segundo en las redes sociales en línea. Para ello, debemos recurrir a los sistemas modernos y eficaces de vigilancia disponibles en el mercado. Este estudio ilustra el uso de estos sistemas.

Palabras claves: Esfera Pública; Capital Social; Conversación; Internet; Big Data.

\begin{abstract}
With the large volume of information currently propagated via the Internet, research on political communication and elections can not be limited to conventional methods of collecting and analyzing data. It is necessary for researchers to invest and take contact with new approaches regarding the events posted every second in Online Social Networks. To do so, we must turn to modern and effective monitoring systems available on the market. This study illustrates the use of these systems.
\end{abstract}

Keywords: Public Sphere; Social Capital; Conversation; Internet; Big Data.

1 Trabalho apresentado à sexta edição da Revista Ação Midiática - Estudos em Comunicação, Sociedade e Cultura, publicação ligada ao Programa de Pós-Graduação em Comunicação, da Universidade Federal do Paraná.

2 Publicitário, Professor Universitário na UNIMEP e na PUC-Campinas, Mestre em Comunicação Social pela UMESP e Doutorando em Ciências da Comunicação pela ECA/USP. E-mail: realvic@gmail.com 


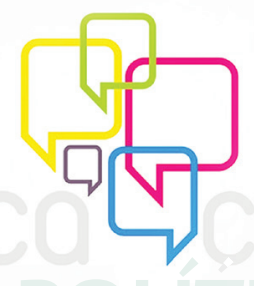

ação mididiática

N. 6 | Ano 2013

\section{Universidade Federal do Paraná I Programa de Pós-Graduação em Comunicação}

\section{Introdução}

Antes do advento das redes de relacionamento online e das mídias sociais as pesquisas sobre os processos comunicacionais utilizavam métodos empíricos baseados em amostras obtidas a partir de questionários, entrevistas e vários outros processos que permitiam compreender as características de um determinado universo.

Mas, atualmente, qualquer pessoa conectada pela internet pode ser um formador de opinião em potencial e tem condições de atingir em poucos segundos uma audiência muito maior que os meios de comunicação tradicionais. Dessa forma, uma simples amostra pode não ser suficiente para analisar o fluxo de informação. $\mathrm{O}$ volume de dados tornou-se muito maior, mais dinâmico e as pessoas passaram a se expressar espontaneamente e com muito mais intensidade sem terem de ser questionadas para dizer o que pensam sobre um determinado assunto.

Os pesquisadores e profissionais de comunicação que pretendem desenvolver estudos sobre o impacto das conversações cotidianas no século XXI, seja sobre marcas, notícias ou mesmo campanhas eleitorais, como é o caso deste estudo, não podem deixar de levar em conta as manifestações que trafegam pela internet. O grande desafio é dominar técnicas e métodos de coleta e análise diante do gigantesco volume de dados.

O presente texto é na verdade um modesto ensaio, portanto deve ser considerado muito mais como um projeto em fase de testes de uma pesquisa mais ampla e aprofundada a ser desenvolvida, em nível de tese de doutorado, durante as Eleições Presidenciais Brasileiras de 2014, sob orientação da professora Heloiza Matos, no Programa de Pós Graduação em Comunicação da ECA/USP.

A intenção aqui é discutir brevemente alguns conceitos teóricos considerados fundamentais e que serão aplicados na tese, quais sejam: Esfera Pública, Capital Social, Conversação e Deliberação Online.

Porém, o objetivo principal destas páginas, é compartilhar a experiência de testar um sistema informatizado de Monitoramento de Mídias Sociais, tendo em vista a necessidade de se utilizar algum destes para auxiliar na coleta efetiva e análise dos dados disponíveis na rede. Existem muitos softwares que oferecem este tipo de serviço, alguns gratuitos e outros pagos, conforme será exposto adiante, no entanto é muito raro encontrar pesquisas e artigos em comunicação que explicam de forma clara e didática como fazer o trabalho de Monitoramento ou como funcionam os softwares. Normalmente, os pesquisadores apresentam diretamente a análise dos dados e não abordam como foi o processo de extração e mapeamento dos dados nas Mídias Sociais.

Neste sentido, tomamos como exemplo aqui os dois principais pré-candidatos às Eleições Presidenciais Brasileiras 2014 e testamos um dos softwares disponíveis no mercado 

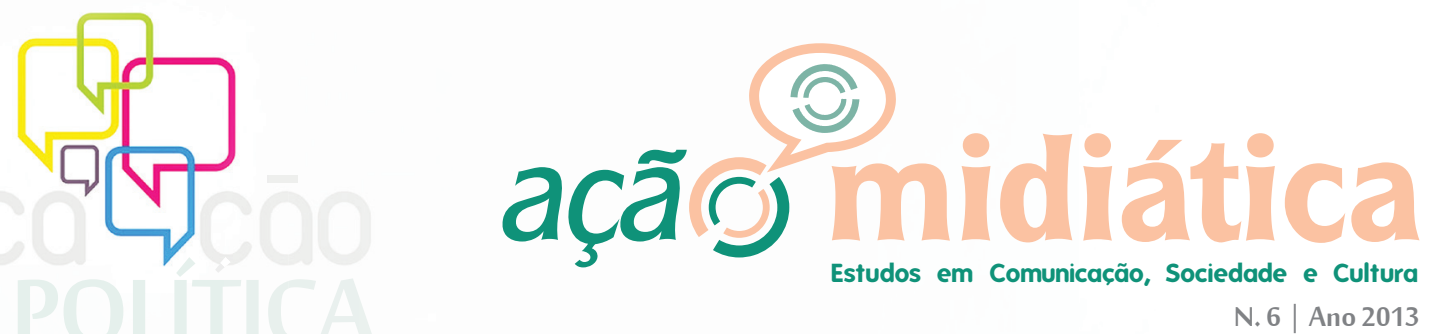

Universidade Federal do Paraná | Programa de Pós-Graduação em Comunicação

durante três dias aleatórios de dezembro/2013, com o propósito de apresentar as principais etapas do processo de Monitoramento nas Mídias Sociais.

A seguir serão feitas breves considerações sobre os conceitos teóricos relacionados ao tema, na sequência uma contextualização sobre a internet no Brasil e finalmente a aplicação do sistema Buzzmonitor na coleta e análise de postagens sobre Dilma Rousseff e Aécio Neves durante os dias 21 e 23/12/2013 no Facebook.

\section{Esfera Pública e Capital Social}

A perspectiva de Habermas, na primeira fase de suas reflexões, marcada pela publicação de "Mudança estrutural na Esfera Pública", no início da década de 1960, considera a esfera pública como "um sistema de alarme dotado de sensores não especializados, porém, sensíveis no âmbito de toda a sociedade". Assim:

(...) a esfera pública tem que reforçar a pressão exercida pelos problemas, ou seja, ela não pode limitar-se a percebê-los e a identificá-los, devendo (...) tematizá-los, problematizá-los e dramatizá-los de modo convincente e eficaz, a ponto de serem assumidos e elaborados pelo complexo parlamentar (HABERMAS, 2003, p. 91).

Segundo Ângela Marques (2008, p. 24) “o conceito de esfera pública aparece ligado à ascensão da burguesia e aos espaços nos quais os integrantes dessa classe se reuniam publicamente para argumentar e expressar razões e juízos acerca de questões e problemas relativos à coletividade". A partir disso, a autora menciona a abordagem negativa de Habermas diante dos meios de comunicação como não sendo benéficos à constituição e ao fortalecimento de uma esfera pública voltada para o esclarecimento recíproco. Marques vai além e aponta a influência de Adorno e Horkheimer ao conduzir Habermas a afirmar que:

\footnotetext{
Os meios de comunicação e, principalmente, a imprensa, seriam os responsáveis pela perda da capacidade crítica do público e pelo conseqüente declínio da esfera pública, uma vez que perderam sua função crítica para atuarem 'apenas como transmissores de propagandas' (MARQUES, 2008, p. 24).
}

Sendo que o princípio de "publicidade", nesse contexto apontado por Marques ao citar Habermas, adquire dois sentidos distintos, mas complementares: o primeiro relativo ao "dar a ver", tornar pública a troca de argumentos entre cidadãos; e o segundo confere à publicidade o status de "regulador" do processo de justificação pública, chegando a impor constrangimentos à ação e ao discurso dos interlocutores. Assim, a crítica de Habermas nessa abordagem inicial de esfera pública relacionada à mídia, destaca que os meios de comunicação passaram a "fabricar" uma opinião "não-pública” cuja origem não é o processo de troca pública de razões, mas o 


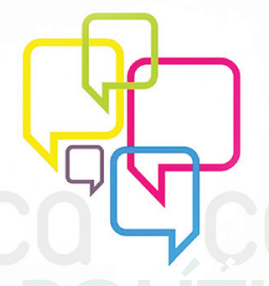

ação I) Midiática

N. 6 | Ano 2013

\section{Universidade Federal do Paraná I Programa de Pós-Graduação em Comunicação}

Segundo Habermas (2003, p. 106) a sociedade civil pode, "em certas circunstâncias, ter opiniões públicas próprias, capazes de influenciar o complexo parlamentar (e os tribunais), obrigando o sistema político a modificar o rumo do poder oficial”. Todavia, a chamada sociologia da comunicação de massas não acredita nas alternativas das tradicionais esferas públicas do Ocidente, todas elas altamente dominadas pelo poder e, por conseguinte, pela mídia.

\footnotetext{
Movimentos sociais, iniciativas de sujeitos provados e de foros civis, uniões políticas e outras associações, numa palavra, os agrupamentos da sociedade civil, são sensíveis aos problemas, porém os sinais que emitem e os impulsos que fornecem são, em geral, muito fracos para despertar a curto prazo processos de aprendizagem no sistema político ou para reorientar processos de decisão (HABERMAS, 2003, p. 107).
}

O filósofo defende a existência de três tipos de esfera pública, de acordo com o nível de densidade da comunicação, complexidade organizacional e alcance:

1) Esfera Pública Episódica: representada por encontros e reuniões casuais entre pessoas conhecidas, por exemplo, em bares e cafés;

2) Esfera Pública Organizada: com finalidades e objetivos melhor definidos, formada a partir de encontro de pais, eventos culturais, reuniões de partidos e congressos de igrejas;

3) Esfera Pública Abstrata: produzida pela mídia, contando com a participação de leitores, ouvintes e espectadores singulares e espalhados globalmente.

Inseridos nesses vários tipos de esfera pública:

(...) existem atores que podem ser identificados como partidos políticos ou como organizações econômicas, como representantes de grupos profissionais, de associações protetoras de inquilinos etc., ao passo que outro tipo de atores tem que produzir primeiro as características que os identificam. Isso pode ser constatado claramente em movimentos sociais que atravessam inicialmente uma fase de autoidentificação e de autolegitimação (o que também vale para atores da sociedade civil em geral); mas tarde eles continuam a exercer uma "identity-politics", paralela às suas políticas pragmáticas - pois, eles têm que certificar-se, a cada passo, de sua identidade (HABERMAS, 2003, p. 109).

Paralelamente, Peter Dahlgren (2009, p. 158) apresenta a morfologia social baseada em redes como uma opção que vem crescendo e sendo utilizada para compreender o mundo moderno. Ele argumenta que as atualizações feitas por Habermas sobre os conceitos de esfera pública $(1996,2006)$, trabalham basicamente com o modelo de redes, apesar de não mencionar 


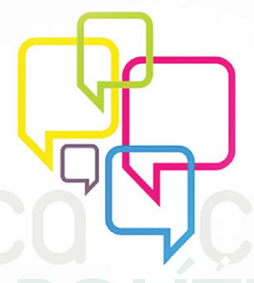

açãô Mididiática

N. 6 | Ano 2013

\section{Universidade Federal do Paraná I Programa de Pós-Graduação em Comunicação}

diretamente a internet naquelas análises.

Na sequência de pensamento, Dahlgren considera a expressão "Sociedade de Rede", ao invés de "Sociedade da Informação", como uma metáfora mais acessível para estudar as tendências de desenvolvimento e a realidade social. Dessa forma, ele recorre e adapta a proposta de tipologia de Nieminen (2007), que divide as redes em quatro possibilidades:

1) Redes Associativas: mais informais e essencialmente voluntárias (relações de amizade, hobby, por exemplo);

2) Redes Societais: relações de pertencimento a uma categoria (profissional, por exemplo), a partir de certas circunstâncias sociais;

3) Redes Afirmativas ou de Interesse: tem caráter deliberativo e objetivo de influenciar decisões, apresentam viés político e de engajamento público;

4) Redes Impostas: relações de nacionalidade, mais extensas (envolve os cidadãos, por exemplo) e com atribuições de direitos e obrigações.

$\mathrm{O}$ autor argumenta que podemos viver praticamente a maior parte do tempo entre essas redes sociais. Além disso, vivemos cada vez mais nessas redes com a ajuda das tecnologias da informação. E aqui, Dahlgren (2009, p. 159) retoma a análise de Capital Social de Putnam (2000), afirmando a importância das redes no sentido de que, quanto mais uma pessoa estiver conectada, melhor poderá exercer sua cidadania. Além disso, ao participar de diferentes redes sociais, as pessoas podem representar pontos de intersecção, por meio dos quais diferentes redes se conectam, dessa forma ela tende a ser bem aceita ou importante nas redes em que participa. E boa parte desse status deriva da capacidade da pessoa de dialogar com a tecnologia e com a internet.

Potencialmente, a ação política pode surgir em qualquer dessas redes, mas é no terceiro tipo que a agência cívica geralmente se manifesta. Justamente esse tipo de rede social afirmativa, formada por interesse e com caráter deliberativo, poderia servir como contraponto a esfera pública formada pela mídia, denominada por Habermas como abstrata e que, segundo os argumentos dele, pode funcionar como barreira, já que os jornalistas coletam informações e decidem os temas/questões que ganham visibilidade. "Esses processos de seleção tornam-se fonte de uma nova espécie de poder, ou poder da mídia, o qual não é controlado suficientemente pelos critérios profissionais" (HABERMAS, 2003, p. 110). De acordo com o pensamento de Habermas:

(...) os produtores da informação impõem-se na esfera pública através de seu profissionalismo, qualidade técnica e apresentação pessoal. Ao passo que os atores coletivos, que operam fora do sistema político ou fora das organizações sociais e associações, têm normalmente menos chances de influenciar conteúdos e tomadas de posição dos grandes meios (HABERMAS, 2003, p. 110). 


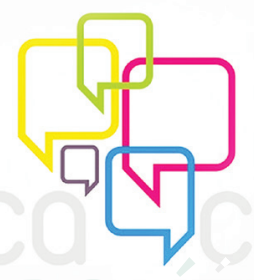

\section{açãô \\ Estudos em Comunicação, Sociedade e Cultura \\ N. 6 | Ano 2013}

\section{Universidade Federal do Paraná | Programa de Pós-Graduação em Comunicação}

1) Estrutura Comunicativa

a. Identificação: participantes são anônimos ou se identificam;

b. Abertura e liberdade: qualquer pessoa pode participar, as conversas são "dominadas" por poucos ou todos podem se expressar;

c. Agenda da discussão: os temas são livres ou propostos pelos responsáveis pela hospedagem do fórum;

d. Moderação: os responsáveis exercem algum tipo de interferência; controlando, organizando ou promovendo os debates;

e. Espaço público forte ou fraco: os participantes sentem que seu envolvimento é reconhecido ou gera resultados políticos concretos.

2) Cultura Política e Ideologia

a. Diferenças culturais entre regiões: perfil geral dos participantes;

b. Tipo do ator político a hospedar o debate: características relevantes sobre os responsáveis pelo fórum;

c. Ideologia dos participantes: preferências expressas abertamente pelo público - em alguns casos é necessário realizar uma survey para obter a confirmação;

d. Tópico de debate: assunto principal em discussão.

3) Design e Conteúdo: Descrição a respeito da funcionalidade do site em que o fórum acontece, relacionada com a facilidade de navegação e de uso das ferramentas de participação e deliberação. Quanto ao conteúdo, Sampaio (2011, p. 205) explica que “deve ser claro, conciso e permitir tanto uma leitura rápida quanto uma pesquisa aprofundada sobre o assunto, considerando, assim, os diferentes níveis de informação dos usuários".

Quanto ao Processo Discursivo, Sampaio define cinco critérios, e os subdivide em itens a serem identificados e preenchidos na análise, servindo neste caso a constatações de ordem quantitativa (critérios de 1 a 3 ) e qualitativa (critérios 4 e 5). É importante explicar que as anotações sobre os critérios de 1 a 3 devem ser feitas para cada mensagem postada, sendo mais facilmente visualizadas em forma de planilhas com percentuais. Sampaio (2011, p. 205) também argumenta sobre a necessidade de ser realizada uma primeira filtragem nas mensagens a serem analisadas, a fim de computar apenas aquelas consideradas "relevantes", e define as que devem ser desconsideradas como: 


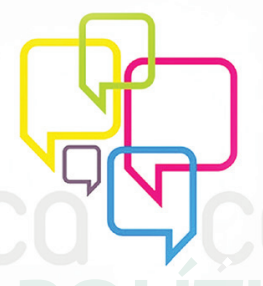

ação (3) midiática

N. 6 | Ano 2013

\section{Universidade Federal do Paraná | Programa de Pós-Graduação em Comunicação}

As mensagens irrelevantes geralmente não tratam do tópico discutido (off-topic), são propagandas (spam) ou ainda sem demandas. (...) tratam como irrelevantes as mensagens que não tenham perguntas, respostas ao tópico, sugestões ou simplesmente demandas em relação a outros atores ou ao assunto (SAMPAIO, 2011, p. 205).

A principal preocupação de Sampaio (2011, p. 206), quanto às mensagens irrelevantes, é que um alto índice delas pode indicar um baixo comprometimento com a discussão, e consequentemente, pode sugerir um baixo índice de deliberatividade.

Sampaio também julga interessante comentar se a mensagem é um questionamento inicial, inaugurando uma nova discussão, ou se é uma resposta a um tópico já aberto. Seguem os critérios do Processo Discursivo:

1) Tematização e crítica racional

a. Dialógica: mensagens com respostas, item também denominado como Reciprocidade;

b. Monológica: mensagens sem respostas;

c. Justificação Externa: usuário cita fontes externas para justificar seu argumento (fatos, dados, notícias, etc.);

d. Justificação Interna: utilizada valores e ponto de vista próprio, baseado em histórico pessoal (testemunho);

e. Posição: afirma uma posição, mas não apresenta justificativa.

2) Reflexividade

a. Persuasão: sinais de que um usuário se sente persuadido pela argumentação de outro participante;

b. Progresso: usuário reflete sobre outra postagem, responde com novos argumentos;

c. Radicalização: reação negativa a outra postagem, usuário radicaliza sua opinião anterior e não demonstra possibilidade de rever sua posição inicial.

3) Ideal Role Taking: Pode ser traduzida como "tomar o lugar do outro", define situações de respeito para escutar e dar atenção às colocações dos outros participantes. Segundo Sampaio (2011, p. 208), "é praticamente o primeiro pré-requisito de uma deliberação de qualidade".

a. Respeito Implícito: não há posições negativas, mas também não há positivas;

b. Respeito Explícito: quando há pelo menos uma posição positiva explícita;

c. Sem Respeito - rude: ofensas, ironias, ataques pessoais, etc.; 

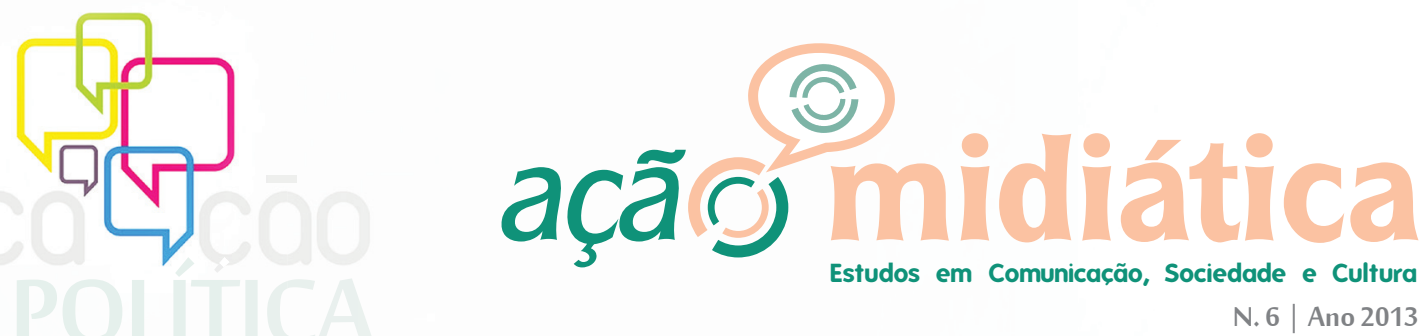

\section{Universidade Federal do Paraná | Programa de Pós-Graduação em Comunicação}

d. Sem Respeito - incivil: preconceito ou ataque contra princípios democráticos;

e. Continuidade: média de mensagens por dia.

4) Inclusão e Igualdade Discursiva: os dados qualitativos identificados neste critério podem já ter sido obtidos na parte da Contextualização, portanto o fundamental aqui é reunir informações para verificar o grau de inclusão digital dentro da cobertura de participação do fórum online. Devendo observar os dois itens abaixo.

a. Pessoas com acesso à internet

b. Número de postagem por pessoas

5) Autonomia do Estado e do poder econômico: análise qualitativa da atuação de instituições que mantém ou financiam o fórum online.

O modelo de análise de deliberação online proposto por Sampaio, comentado nestas páginas, oferece uma ampla base metodológica para o desenvolvimento de pesquisas científicas sobre conversações em ambientes interconectados. Mas, para garantir sua eficaz aplicação, devemos considerar a realidade atual da internet no Brasil, e dominar algumas das técnicas de monitoramento e análise dos dados das redes sociais.

\section{Internet e Mídias Sociais no Brasil}

De acordo com dados divulgados em outubro/2013 pelo Ibope Media, o número de pessoas com acesso à internet no Brasil chegou a 105,1 milhões no segundo trimestre de 2013, o que representa um crescimento de $3 \%$ na comparação com os 102,3 milhões, registrados no trimestre anterior. Os dados são públicos, estão disponíveis no próprio website do Ibope e foram divulgados por diversos portais de notícias. O estudo considera o volume total de acesso à internet em qualquer ambiente como domicílios, trabalho, lan houses, escolas, bibliotecas, espaços públicos e outros locais.

Estes dados colocam o Brasil como o terceiro país com maior número de usuários da internet, ficando atrás apenas dos Estados Unidos e do Japão, que ocupam respectivamente a primeira e a segunda colocação neste ranking.

Quanto ao uso das redes sociais online, mais de 70\% dos internautas brasileiros possuem perfil no Facebook, ou seja, mais de 76 milhões de pessoas responsáveis por colocar o Brasil também em terceiro lugar neste ranking mundial, sendo superado apenas pelos Estados Unidos, que mantém o primeiro lugar, e pela Índia, que passou recentemente a ocupar o segundo lugar. No entanto, o Brasil continua sendo o país com maior número de novos usuários por ano, segundo dados oficiais do próprio Facebook. 


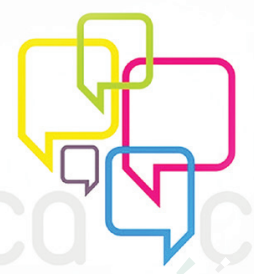

ação) Imidiática

N. 6 | Ano 2013

\section{Universidade Federal do Paraná | Programa de Pós-Graduação em Comunicação}

Sem dúvida estes são números muito expressivos e colocam o país num patamar de importante representatividade de presença digital na escala global. Mas, simplesmente o número de usuários não representa todo o potencial de uma rede social, informações como o número de acessos ou visitas são fundamentais para determinar o fluxo e a atualização das conversações online. Por exemplo, o número de contas pessoais ativas em serviços como o Orkut e o Twitter ainda são bastante altos no Brasil, porém segundo apurou a pesquisa do Experian Marketing Service (Figura 1) em outubro de 2013, o percentual de acessos às duas redes de relacionamento acima mencionadas é praticamente inexpressivo se comparado ao Facebook que detém 73,5\% das visitas feitas a redes sociais, enquanto o Orkut possui $0,97 \%$ e o Twitter $0,90 \%$.

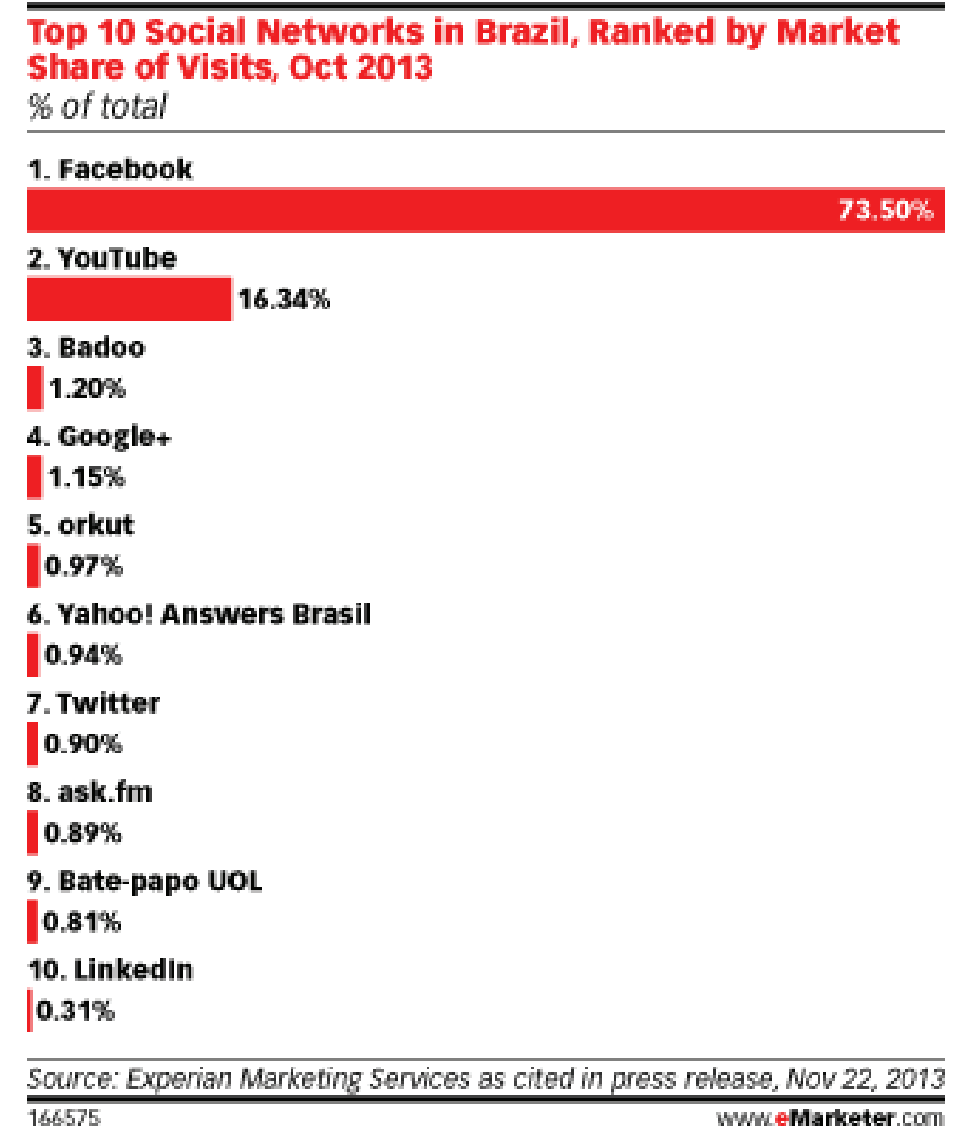

Figura 1: Percentual de acesso a redes sociais no Brasil em outubro/2013.

Fonte: www.emarketer.com.

\section{Monitoramento nas Mídias Sociais}

Diante da breve contextualização apresentada acima sobre a internet no Brasil, parece bastante evidente a força desta nova mídia na transmissão de informação e na formação da opinião pública. Através das mídias sociais uma nova perspectiva sobre os conceitos de Esfera Pública e Capital Social podem ser traçados. 


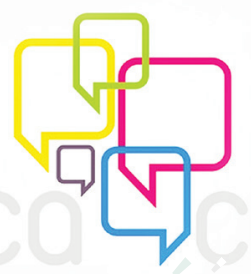

Para tanto, faz-se necessário compreender como os estudos em comunicação podem extrair e analisar o gigantesco volume de dados trafegados a cada segundo pela internet. Com o advento das novas tecnologias, os bancos de dados tornaram-se ilimitados e dinâmicos, e passaram a ser chamados de Big Data. Ganhamos, assim, uma riquíssima fonte de informações sobre comportamentos e tendências como nunca houve na história. A tarefa dos pesquisadores e dos profissionais é buscar ferramentas eficazes e desenvolver métodos adequados para garimpar os dados que efetivamente interessam.

A metodologia de Análise de Redes Sociais - ARS tem sido cada vez mais empregada nos estudos sobre comunicação, caminha em paralelo e, muitas vezes, complementa outros métodos mais tradicionais e consolidados como Estudo de Campo, Etnografia, Análise de Conteúdo, Focus Group, etc.

A aplicação da ARS depende fundamentalmente das estratégias de Monitoramento das Mídias Sociais. A estrutura de monitoramento pode ser baseada na seguinte definição:

(...) coleta, armazenamento, classificação, categorização, adição de informações e análise de menções online públicas a determinado(s) termo(s) previamente definido(s) e seus emissores, com os objetivos de: (a) identificar e analisar reações, sentimentos e desejos relativos a produtos, entidades e campanhas; (b) conhecer melhor os públicos pertinentes; e (c) realizar ações reativas e pró-ativas para alcançar os objetivos da organização ou pessoa de forma ética e sustentável (SILVA, 2010, p. 43).

Devido ao grande volume de dados disponíveis online, pode ser inviável ou mesmo impossível dispor de recursos humanos suficientes para monitorar 24 horas por dia as postagens e atualizações em torno de um determinado assunto nas redes sociais. É preciso, portanto, recorrer a softwares capazes de auxiliar no processo de monitoramento. Existem diversos modelos no mercado, os quais podem apresentar funcionalidades, layouts e recursos bastante distintos. Alguns são distribuídos gratuitamente e outros são comercializados pelas empresas desenvolvedoras que oferecem, em alguns casos, versões limitadas para testes. Também é possível desenvolver sistemas próprios dependendo do domínio de programação e prática com algoritmos.

Basicamente, os softwares de monitoramento são divididos em duas categorias: os parciais e os plenos. Como as próprias nomenclaturas sugerem, os primeiros são mais limitados que os segundos, servem basicamente como ponto de partida e definição de estratégia para um posterior monitoramento mais aprofundado. O Google e o Facebook, por exemplo, oferecem alguns softwares parciais dentro de suas próprias plataformas, capazes de rastrear com certa facilidade algumas informações, também existem outros serviços gratuitos de monitoramento 


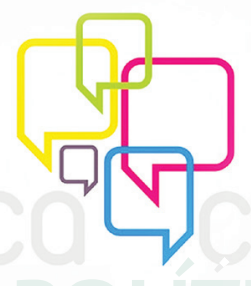

açãô Imidiática

N. 6 | Ano 2013

Universidade Federal do Paraná | Programa de Pós-Graduação em Comunicação

parcial como: o Social Mention e o Topsy. Mas, são os softwares plenos que oferecem as ferramentas mais robustas para o tratamento de Big Data, e consequentemente permitem o efetivo Monitoramento das Mídias Sociais, agregando todas as etapas numa única plataforma. Existem inúmeros serviços desse tipo, cada qual possuindo determinados pontos positivos e negativos, conforme análise detalhada apresentada por Tarcízio Silva (2011), dois dos softwares plenos mais conhecidos e utilizados são o Radian6 e o Scup.

Independentemente do sistema escolhido, ou até mesmo no eventual caso de mais de um deles ser utilizado, o mais importante no processo de monitoramento é ter clareza e respeitar as seguintes etapas:

1) Definir objetivos do projeto;

2) Selecionar palavras-chave (termos, tags, etc);

3) Estipular filtros (rede social, tempo, segmentação, etc);

4) Crias categorias (positivas, negativas, neutras);

5) Sistematizar apresentação de resultados (menções, gráficos, nuvens de palavras, grafos).

A seguir será apresentado um exemplo de Monitoramento de Mídias Sociais, ilustrando as etapas mencionadas acima e tomando como base os fundamentos abordados neste texto.

\section{Exemplo de Monitoramento utilizando o sistema Buzzmonitor}

Existem inúmeros sistemas de monitoramento disponíveis no mercado, é interessante que cada pesquisador faça alguns testes com os mais conhecidos, indicados, por exemplo, no estudo de Silva (2011) ou a partir de outras fontes de referência, tome contato com as plataformas e finalmente escolha aquela que melhor atenda as suas necessidades. No caso do presente estudo, o sistema que apresentou as melhores condições de coleta e análise de dados foi o Buzzmonitor, desenvolvido pela empresa multinacional E.life. A seguir será justificado o uso do referido sistema a partir da exemplificação das cinco etapas mencionadas no subitem anterior e que foram aplicadas neste projeto de pesquisa:

1) Quanto aos objetivos, este estudo teve como principal foco testar um software de monitoramento pleno capaz de extrair manifestações publicadas por usuários do Facebook sobre dois pré-candidatos às Eleições Presidenciais Brasileiras de 2014. Muitas pesquisas similares optam em analisar as postagens feitas pelo Twitter ao invés do Facebook, uma das justificativas para isso é o fato da maioria dos softwares rastrear com mais facilidade a API (Application Programming Interface ou Interface de Programação de Aplicativos) do Twitter. Porém, de acordo com os dados de acessos registrados nas duas redes sociais e apresentados nas páginas acima (73,5\% 

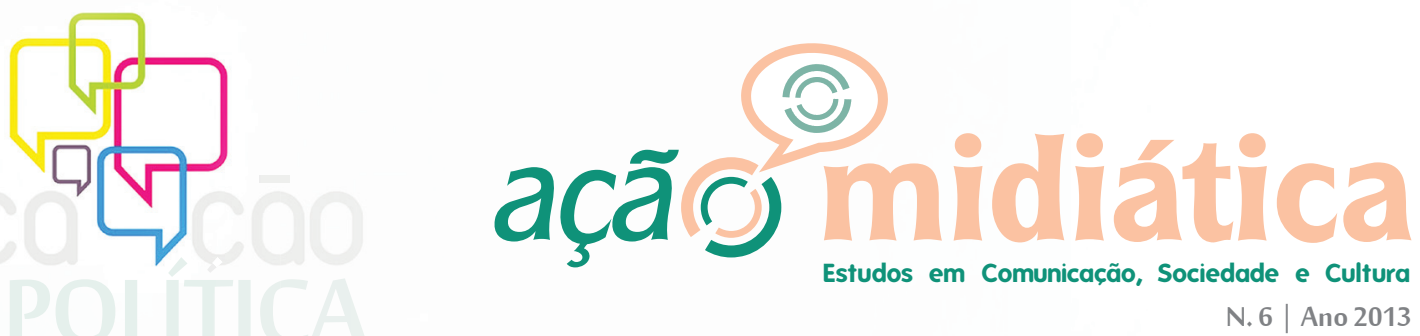

Universidade Federal do Paraná | Programa de Pós-Graduação em Comunicação

Facebook e 0,90\% Twitter), o Facebook foi considerado aqui como sendo a principal Esfera Pública de conversação online e capaz de representar as quatro possibilidades de redes de relacionamento abordadas por Dahlgren (2009). Dos sistemas testados, o Buzzmonitor foi o que apresentou melhor funcionalidade na extração de dados do Facebook, mesmo na versão gratuita disponibilizada online (https://app. buzzmonitor.com.br), ou seja, sem necessidade de pagamento de qualquer taxa e sem ter de fazer download do software foi possível coletar com muita facilidade e abrangência os dados necessários para este breve estudo;

2) A seleção das palavras-chave de pesquisa, também conhecidas como termos ou tags, é o ponto mais importante de um monitoramento de mídias sociais depois da definição dos objetivos e da escolha do sistema a ser utilizado. É baseado nelas que o software faz o rastreio no universo do Big Data, ou seja, caso um termo ou alguma de suas possíveis variações não seja incluído, toda a pesquisa pode falhar. Cada sistema possuiu critérios próprios para inserção das palavras-chave, portanto é fundamental ficar atento às configurações e estudar os tutoriais que normalmente são disponibilizados pelos serviços de monitoramento. No Buzzmonitor, primeiro é necessário criar as "Marcas" a serem monitoradas, neste caso definimos apenas duas, Dilma Rousseff e Aécio Neves, pelo fato de serem os dois principais pré-candidatos conforme as pesquisas de intenção de voto para 2014. Depois da definição das marcas, foram inseridas as seguintes tags, seguindo os critérios do sistema:

a. Dilma Rousseff: dilma (governo OR politica OR eleicao OR eleicoes) OR "dilma rousseff";

b. Aécio Neves: aecio (governo OR politica OR eleicao OR eleicoes) OR "aecio neves".

Não é preciso fazer distinção de maiúsculas, nem de acentos e cedilhas, pois o Buzzmonitor considera automaticamente estas variáveis. No entanto, devem ser utilizados parênteses, aspas e os códigos OR e AND para restringir a busca. $\mathrm{Na}$ presente pesquisa a intenção foi localizar publicações no Facebook que fizessem menção a Dilma e Aécio, mas não "qualquer informação" sobre "qualquer Dilma ou Aécio", mas sim exclusivamente relacionadas aos termos governo, política, eleição ou eleições, por isso o uso destes complementos entre parênteses. Além disso, foram indicados entre aspas os termos "Dilma Rousseff" e "Aécio Neves", a fim de localizar qualquer publicação que utilizasse exatamente estas menções. Poderiam também ser acrescentados possíveis erros de digitação, como por exemplo: Russef ou Roucefi, a fim de garantir a amplitude e totalidade do monitoramento, porém 


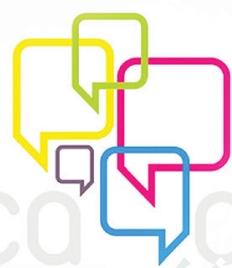

açãô I) Midiática

N. 6 | Ano 2013

\section{Universidade Federal do Paraná | Programa de Pós-Graduação em Comunicação}

estas variáveis foram desconsideradas aqui por se tratar de um ensaio ainda em fase de testes;

3) O terceiro passo é estipular os filtros de pesquisa, ou seja, quais redes sociais desejamos monitorar, por quanto tempo, tipo de publicação, etc. Neste exemplo foi definido exclusivamente o Facebook; com postagens feitas por qualquer perfil pessoal ou página; compostas por textos, imagens ou vídeos; de 21 a 23/12/2013 (foi definido um período curto para facilitar o teste e detectar a variação de comportamento de sábado a segunda-feira). Também foram selecionados três tipos de relatórios oferecidos pelo Buzzmonitor (Figura 2): o Volume Evolution (apresenta a variação no número de postagens ao longo do tempo); o Top Terms (indica os termos mais mencionados no período analisado); e o Top Users (lista os usuários que mais mencionaram os termos pesquisados). Além disso, o software armazena a íntegra de todas as publicações com seus respectivos links na rede social monitorada;

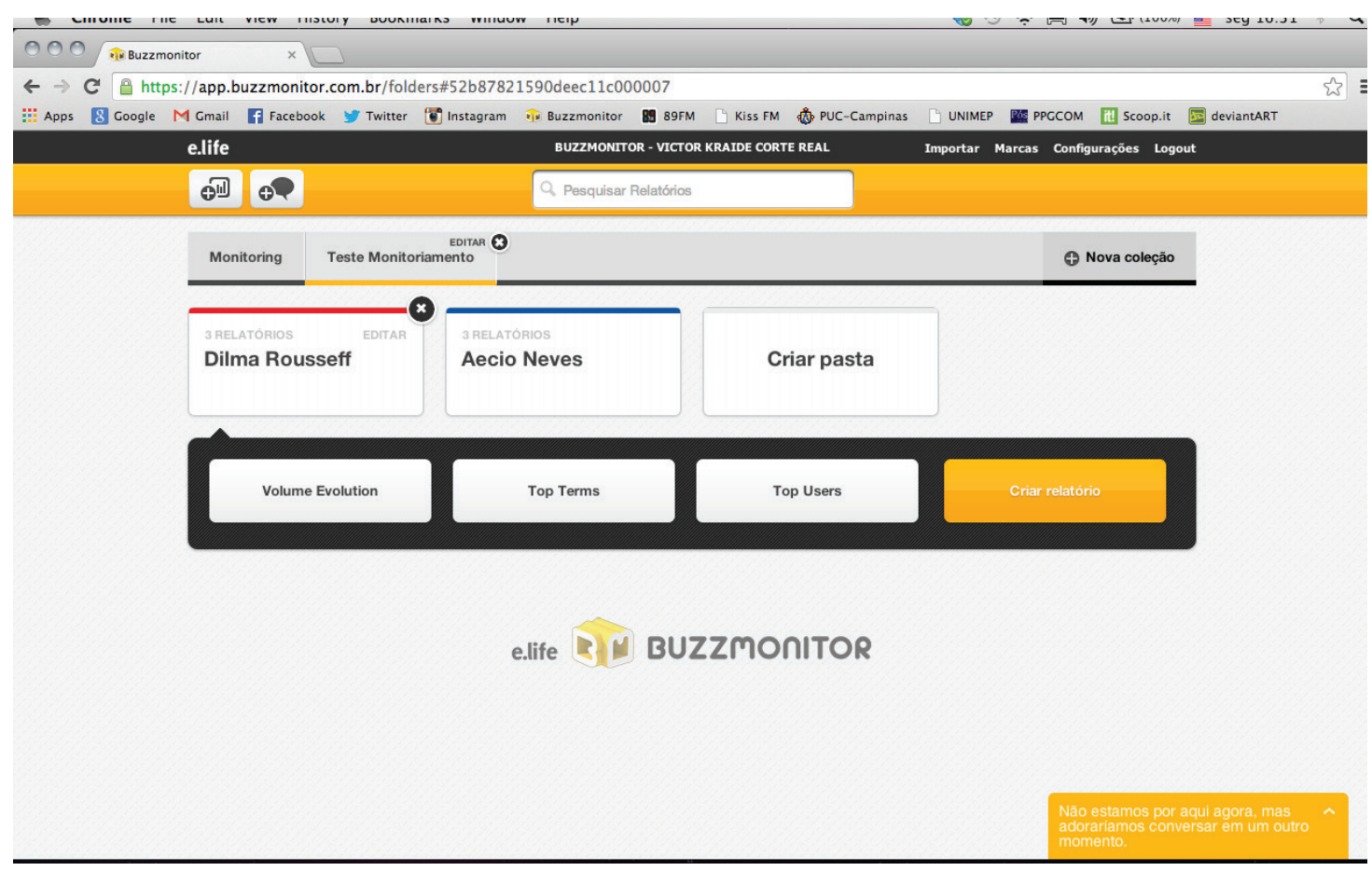

Figura 2: Layout do software Buzzmonitor, a partir da definição de Marcas e Relatórios a serem monitorados. Fonte: https://app.buzzmonitor.com.br.

4) Com toda a estrutura montada é possível dividir as postagens em categorias de análise representadas por sentimentos Positivos, Negativos, Neutros e Mistos. O Buzzmonitor faz isso automaticamente considerando padrões do sistema que 


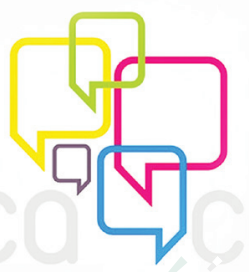

açãô I) Midiática

N. 6 | Ano 2013

\section{Universidade Federal do Paraná | Programa de Pós-Graduação em Comunicação}

considera, por exemplo, publicações contendo as palavras "bom, legal, bacana, etc." como sendo Positivas, "mal, ruim, chato, etc." como Negativas, outras diversas e variadas como Neutras ou Mistas (Figura 3). Obviamente este é um critério que pode apresentar equívocos, por isso é possível alterar manualmente a categoria de cada publicação monitorada;

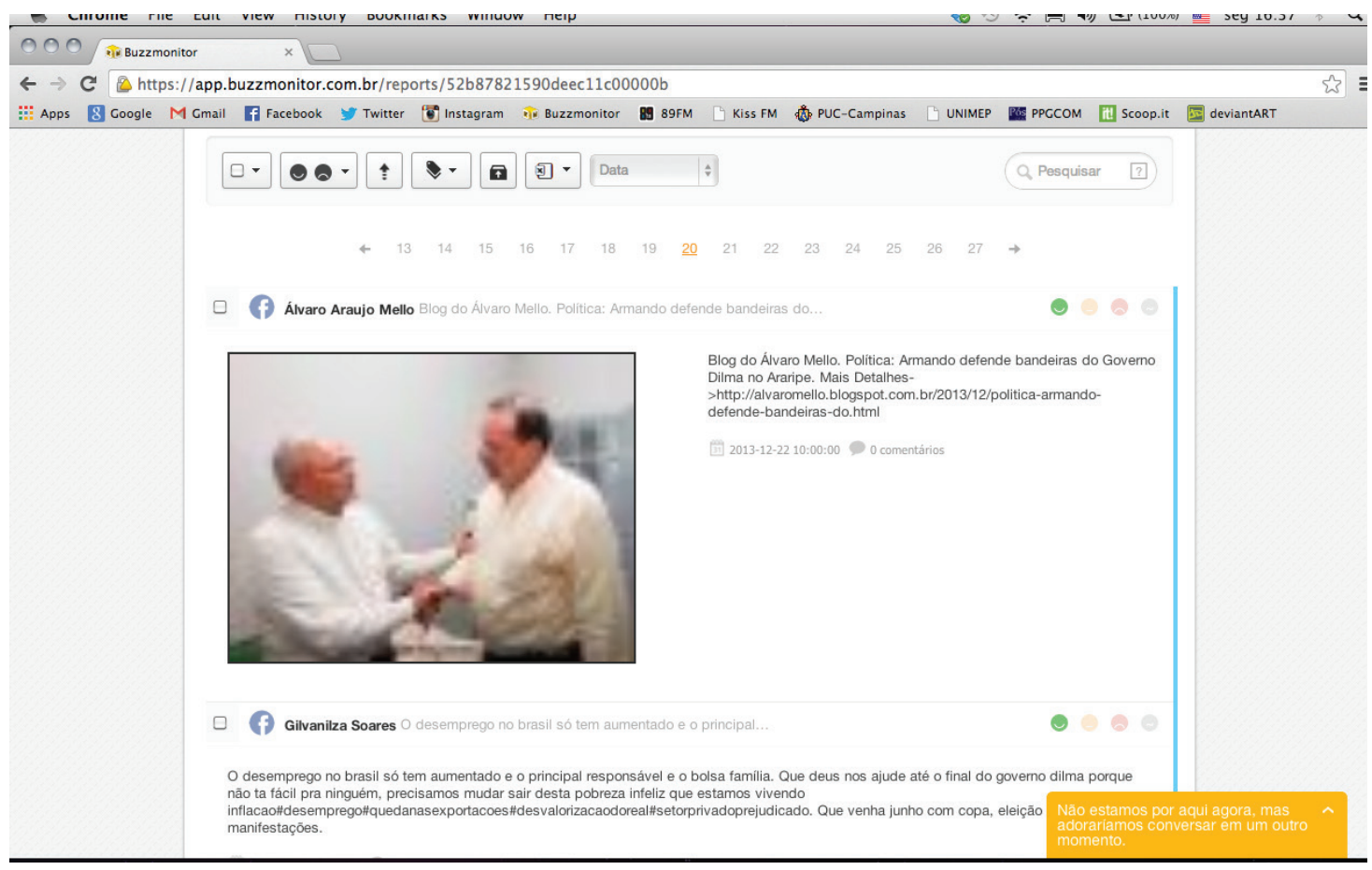

Figura 3: Reprodução das postagens localizadas pelo Buzzmonitor sobre a tag "Dilma" no Facebook. A indicação de categoria é ilustrada no canto superior direito de cada publicação e pode ser alterada manualmente pelo pesquisador. Fonte: https://app.buzzmonitor.com.br.

5) A etapa final de monitoramento corresponde a apresentação dos resultados e análise. Existem softwares que oferecem recursos gráficos que ilustram por meio de "Nuvens de Palavras" os termos mais encontrados, outros apresentam as conexões e nós que interligam os diversos perfis de interação em torno de um determinado assunto (chamados de "Sociogramas", baseados em grafos e clusters). O Buzzmonitor disponibiliza diversas opções gráficas de acordo com os filtros, relatórios e categorias definidos. A representação gráfica facilita muito o processo de análise de um monitoramento, no entanto corresponde aos aspectos mais quantitativos de uma pesquisa. Do ponto de vista qualitativo, fundamental em termos de Análise de Conteúdo, Etnografia e Estudos de Comportamento, o Buzzmonitor oferece muito mais que números e estatísticas ao armazenar também a íntegra e o link de todas as publicações. 


\section{ação midiática}

N. 6 | Ano 2013

\section{Universidade Federal do Paraná | Programa de Pós-Graduação em Comunicação}

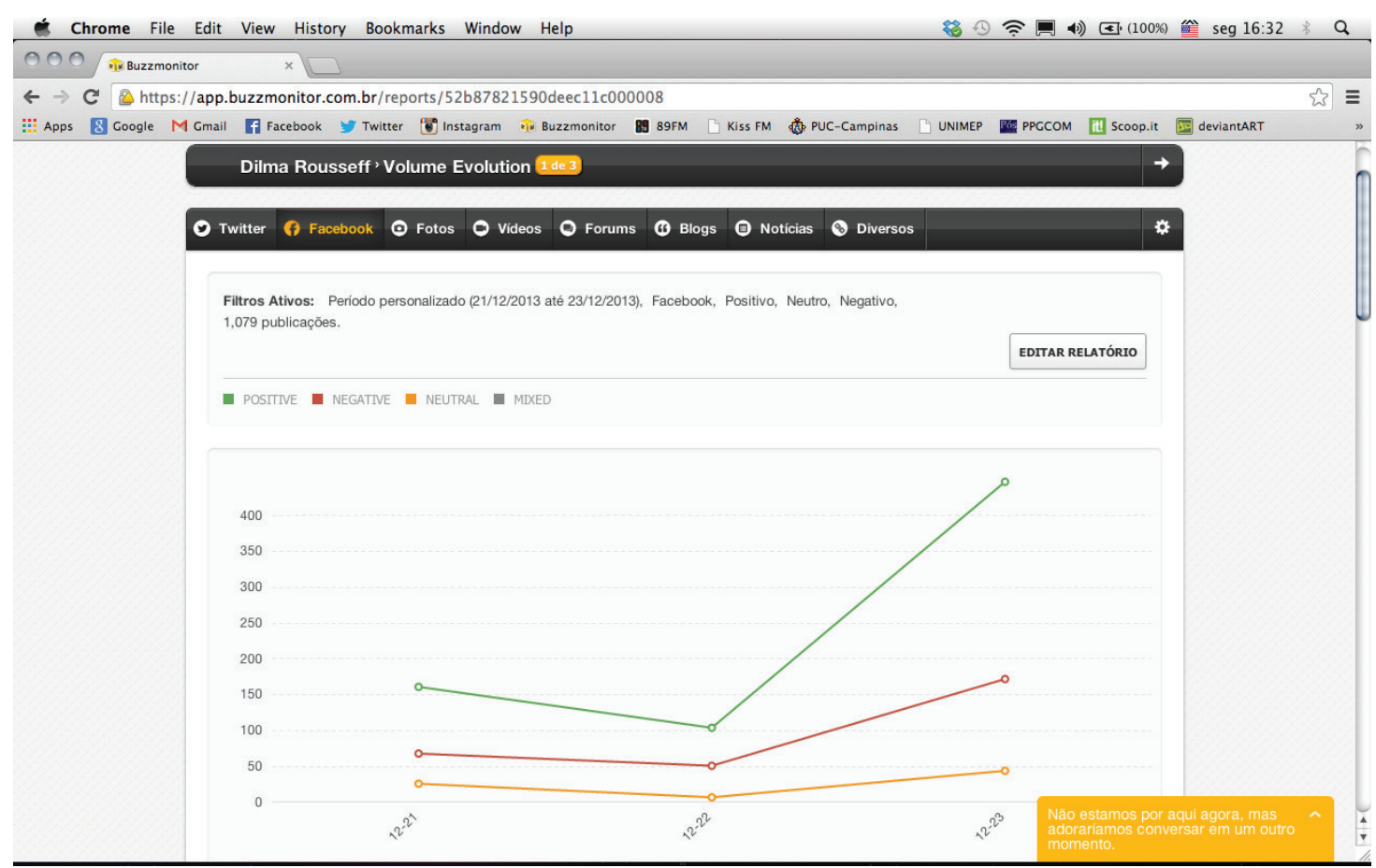

Figura 4: Gráfico Volume Evolution do Buzzmonitor, apresentando a variação no número de postagens sobre "Dilma Rousseff" no Facebook de 21 a 23/12/2013. Fonte: https://app.buzzmonitor.com.br.

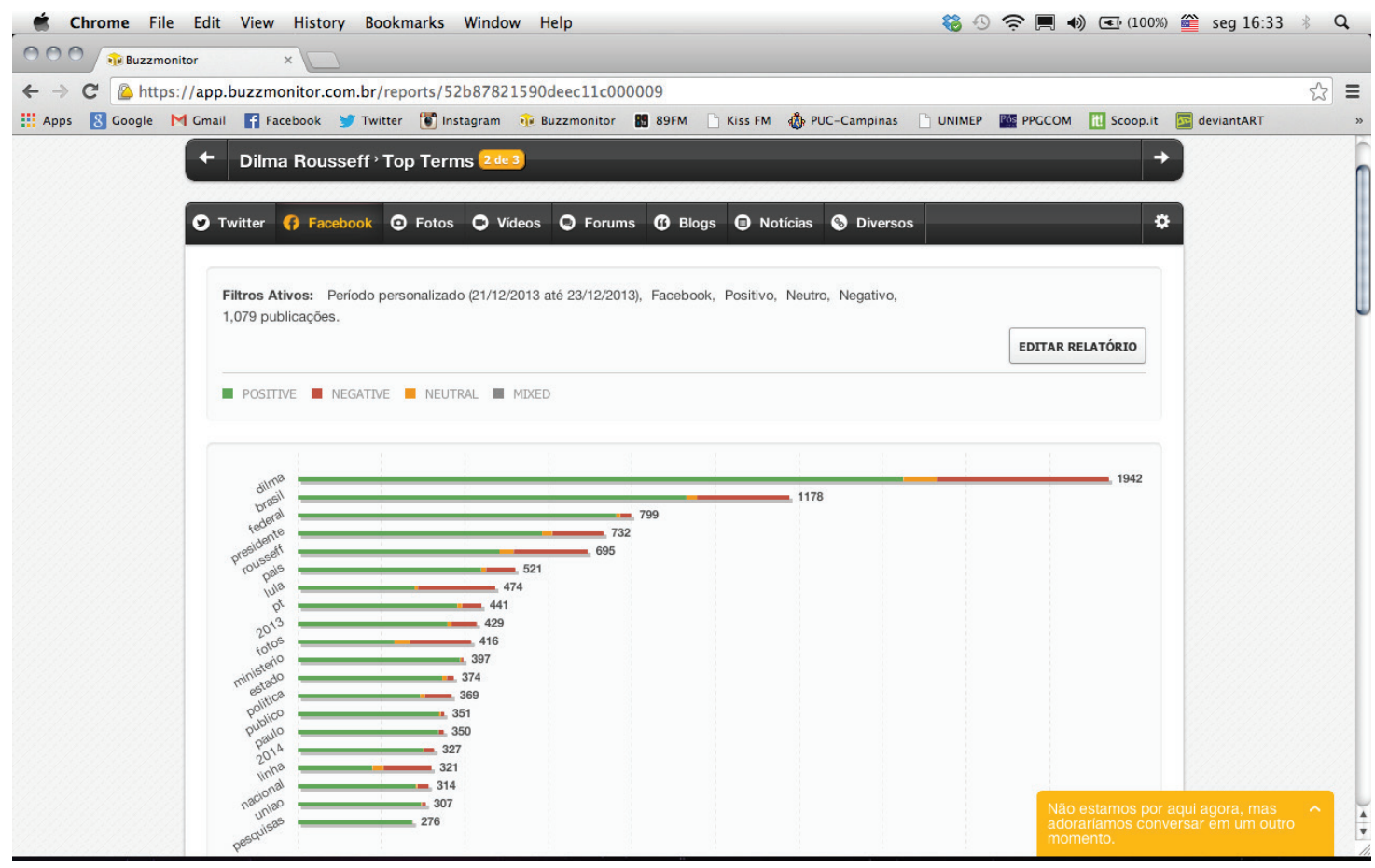

Figura 5: Gráfico Top Terms do Buzzmonitor, apresentando os termos mais mencionados sobre "Dilma Rousseff" no Facebook de 21 a 23/12/2013. Fonte: https://app.buzzmonitor.com.br. 


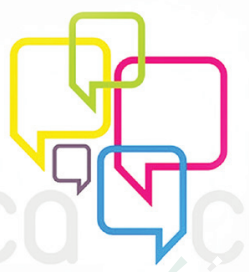

ação) Mididiática

N. 6 | Ano 2013

\section{Universidade Federal do Paraná | Programa de Pós-Graduação em Comunicação}

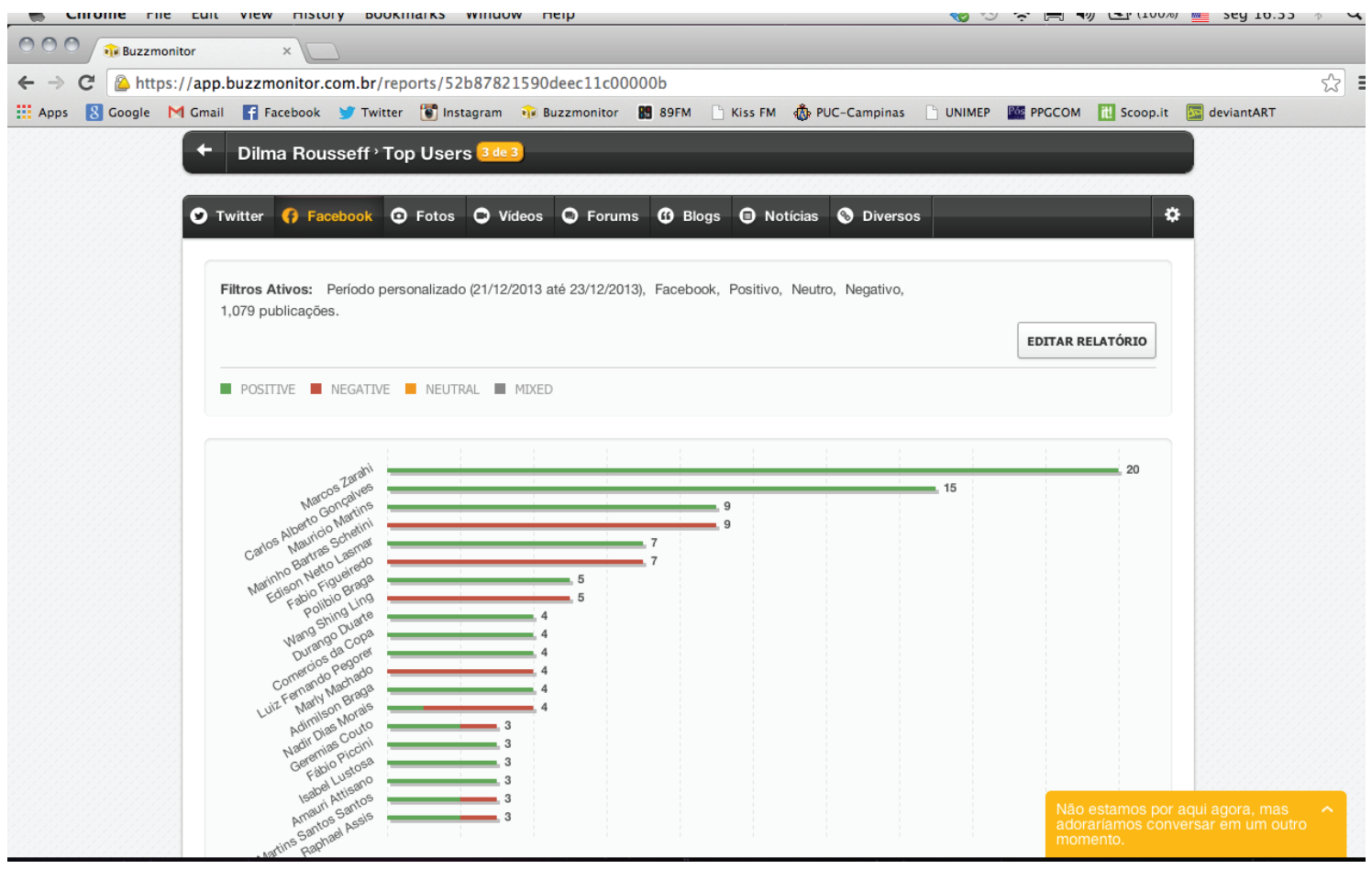

Figura 5: Gráfico Top Users do Buzzmonitor, apresentando os usuários que mais postaram sobre

“Dilma Rousseff” no Facebook de 21 a 23/12/2013. Fonte: https://app.buzzmonitor.com.br.

\section{Considerações}

Durante o período analisado foi possível perceber o enorme potencial dos softwares de Monitoramento de Mídias Sociais no auxílio e viabilização de pesquisas amplas sobre conversação nas redes sociais online. Dos sistemas testados, o Buzzmonitor foi o que apresentou a versão gratuita mais completa e eficaz para mapeamento de menções sobre palavras específicas no Facebook. Outros softwares demonstraram bons resultados no caso de extração de dados do Twitter, no entanto, conforme já foi justificado nas páginas anteriores, o Facebook detém mais de $70 \%$ do acesso diário em mídias sociais no país, o que justifica o foco das pesquisas sobre comportamento e tendências dos usuários a partir deste serviço. Ou seja, considerando os conceitos atuais a respeito de Esfera Pública e de Redes de Relacionamento Online, não existe hoje um espaço na internet com tanto potencial social e de interação como o Facebook.

Sobre os dados obtidos, levando em conta as palavras-chave, os três dias de monitoramento e demais critérios estipulados na plataforma Buzzmonitor, foram constatadas 1.079 publicações sobre Dilma Rousseff e 233 sobre Aécio Neves. Foi percebida uma ligeira queda no volume de postagens do sábado para o domingo e um grande aumento do domingo para segunda-feira, o que representa uma tendência de maior abordagem sobre os assuntos analisados nos dias úteis. Nenhum tema específico apareceu com maior destaque durante a pesquisa. 


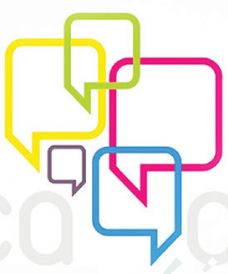

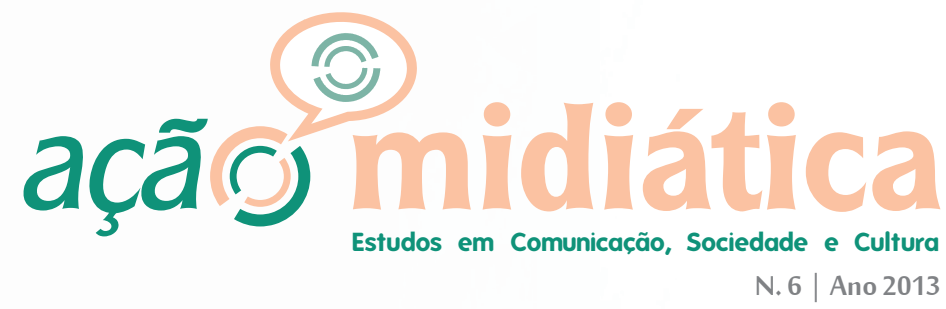

Universidade Federal do Paraná | Programa de Pós-Graduação em Comunicação

In: DOURADO, Danila; SILVA, Tarcízio; CERQUEIRA, Renata; AYRES, Marcel (orgs.). \#MidiasSociais: Perspectivas, Tendências e Reflexões. Florianópolis: Bookess, 2010.

, Tarcízio. Ferramentas de Mensuração e Análise de Mídias Sociais, 2011. Disponível em: http://www.slideshare.net/tarushijio/ferramentas-de-mensuracao-e-analise. Acesso em: 16.dez.2013. 